\title{
ASIPP Guidelines are Practical and Informative: Need a Correction
}

\section{TO THE EDITOR:}

I enjoyed reading the guidelines provided by the American Society of Interventional Pain Physicians (Pain Physician 2007; 10:7-111). The guidelines are extensive, informative, and practical. These continue to be an asset for practices in interventional pain management since 2005.

However, I would like to point out an error. In the evidence section for transforaminal epidural steroid injections (Section 6.2.3.2), the evidence for interlaminar epidural steroid injections is duplicated from Section 6.2.2.2. The evidence in both sections reads as follows:

"In managing lumbar radicular pain with interlaminar lumbar epidural steroid injections, the evidence is strong for short-term relief and limited for long-term relief. In managing cervical radiculopathy with cervical interlaminar epidural steroid injections, the evidence is moderate for short-term improvement and long-term improvement. The evidence is indeterminate in the management of axial neck pain, axial low back pain, and lumbar spinal stenosis."

I will appreciate appropriate correction.

Shishir A. Dhruva, MD

Therapeutic Pain Management Medical Clinic Redding Anesthesia Associates Medical Group 1335 Buenaventura Blvd.

Suite 100

Redding, CA 96001

dhruva@pacbell.net

\section{In Response:}

We appreciate the interest and early recognition of an unfortunate and unmistakable error in the text. However, the information was accurate in the abstract section. This error was corrected immediately in the electronic version. Now section 6.2.3.2 reads as follows:

"The evidence for lumbar transforaminal epidural steroid injections in managing lumbar nerve root pain is strong for short-term and moderate for long-term improvement. The evidence for cervical transforaminal epidural steroid injections in managing cervical nerve root pain is moderate for short-term and longterm improvement. The evidence is limited in managing lumbar radicular pain in postlumbar laminectomy syndrome. The evidence is indeterminate in managing axial low back pain, axial neck pain, and lumbar disc extrusions."

Laxmaiah Manchikanti, MD

CEO

American Society of Interventional Pain Physicians Medical Director

Pain Management Center of Paducah

2831 Lone Oak Road

Paducah, Kentucky 42003

Associate Clinical Professor

Anesthesiology and Perioperative Medicine

University of Louisville, Kentucky 40292

E-mail: drm@apex.net. 